\title{
INTRODUCTION TO VOLUME 17:
}

\author{
PAPERS FROM THE HUGOYE \\ CONFERENCE II: GARSHUNOGRAPHY IN \\ THE SYRIAC TRADITION
}

\author{
J. EDWARD WALTERS \\ PRINCETON THEOLOGICAL SEMINARY
}

The second Hugoye Conference was held on June 22, 2013 on the topic of "Garshunography in the Syriac Tradition." A group of around 50 scholars met in Alexander Library at Rutgers University, joined by around 50 other scholars from various locations throughout the world thanks to the live online stream of the conference by Rutgers' technical staff. At the conference, eight scholars presented papers on the topic of Garshunography, including Aaron Butts, George A. Kiraz, Sebastian Brock, Joseph Moukarzel, Khalid Dinno, István Perczel, Hidemi Takahashi, and Emanuela Braida.

Two of the papers (Butts and Kiraz) focused on the concept of and appropriate terminology for the study of "Garshuni" as a textual phenomenon. The rest of the papers focused on particular iterations of Garshuni writing practices from a variety of languages, cultures, time periods, and contexts including Greek and Latin (Brock), Arabic (Moukarzel, Dinno), Armenian (Takahashi), Malayalam (Perczel), and Neo-Aramaic (Braida). This range of material epitomizes the rich heritage of Garshuni writing practices associated with the Syriac tradition, and also suggests that there is much more work remaining to be done to understand the extent of the practice and the socio-historical conditions that necessitated it. 
Two of the papers from the conference will not appear in this volume (Kiraz, Butts). But the volume will include two submissions by scholars of Garshuni materials who were unable to attend the conference: Peter Zieme and Adam McCollum.

The conference was hosted by Beth Mardutho: The Syriac Institute, the Rutgers University Libraries, the Rutgers Department of African, Middle Eastern, and South Asian Languages and Literature, and the Rutgers Center for Middle Eastern Studies. Several people from Rutgers University deserve our thanks for their involvement in sponsoring this event, in particular Dr. Marianne Gaunt, Vice President for Information Services and University Librarian, and her staff Farideh Tahrani, Grace Agnew, and Isaiah Beard. Special thanks are also due to Prof. Charles Häberl, AMESALL chair.

The next Hugoye conference will be held May 16-17, 2014 at Rutgers University, Alexander Library. The topic for this conference will be "Colophons in the Syriac Tradition." 